\title{
Analysis of novel serum markers of fibrosis and angiogenesis in patients with alcoholic liver cirrhosis
}

\author{
Andrzej Prystupa ${ }^{1, A-F} \oplus$, Paweł Kiciński ${ }^{2, D-E}{ }^{\oplus}$, Dorota Luchowska-Kocot ${ }^{3, B}{ }^{\oplus}$, \\ Grzegorz Nowicki ${ }^{4, F}{ }^{\oplus}$, Grzegorz Dzida ${ }^{1, F} \oplus$, Wojciech Myśliński ${ }^{1, F}{ }^{\oplus}$, Maciej Zakrzewski ${ }^{1, F} \oplus$, \\ Jerzy Mosiewicz ${ }^{1, F \oplus}$, Lech Panasiuk ${ }^{5, F \oplus}$ \\ ${ }^{1}$ Department of Internal Medicine, Medical University, Lublin, Poland \\ 2 Department of Experimental Haematooncology, Medical University, Lublin, Poland \\ ${ }^{3}$ Department of Medical Chemistry, Medical University, Lublin, Poland \\ ${ }^{4}$ Department of Family Medicine and Community Nursing, Medical University, Lublin, Poland \\ ${ }^{5}$ Department of Internal Diseases and Hypertension, Institute of Rural Health, Lublin, Poland \\ A - Research concept and design, B - Collection and/or assembly of data, C - Data analysis and interpretation, \\ $D$ - Writing the article, E - Critical revision of the article, F - Final approval of article
}

Prystupa A, Kiciński P, Luchowska-Kocot D, Nowicki G, Dzida G, Myśliński W, Zakrzewski M, Mosiewicz J, Panasiuk L. Analysis of novel serum markers of fibrosis and angiogenesis in patients with alcoholic liver cirrhosis. Ann Agric Environ Med. 2020 ; $27(4)$ : $568-573$. doi: $10.26444 /$ aaem/127621

\section{Abstract}

Introduction. Alcohol consumption causes acute and chronic liver injury. The clinical forms of alcohol liver disease (ALD) include steatosis, hepatitis, cirrhosis, and hepatocellular carcinoma (HCC) associated with liver cirrhosis.

Objective. The aim of the study was to determine the levels of novel markers of fibrogenesis and angiogenesis in patients with alcoholic liver cirrhosis. Serum levels of angiopoietin-like peptide 4 (ANGPTL-4), asialoglycoprotein receptor 1 (ASGP-R1), and S100 calcium-binding protein A8 (S100A8) were assessed. Levels of hyaluronic acid (Hyal) and collagen IV (Coll IV) werealso determined at various stages of alcoholic liver cirrhosis.

Materials and method. The study group consisted of 72 patients with alcoholic liver cirrhosis, while the control group included 22 healthy subjects without a history of alcohol abuse. The degree of liver cirrhosis was evaluated according to the Pugh-Child criteria (Pugh-Child score). Based on thse scores, patients were assigned to one of three groups: Pugh-Child (P-Ch) A - 21 with stage A, P-Ch B - 23 with stage B and P-Ch C - 28 with stage C liver cirrhosis. Serum levels of markers were determined using ELISA.

Results. The study findings demonstrated higher levels of ANGPTL-4, ASGP-R1, S100A, hyaluronic acid and serum collagen IV in the group of patients with alcoholic liver cirrhosis, compared to the control group. Furthermore, their levels increased with the progression of alcoholic liver cirrhosis.

Conclusions. The biomarkers analysed in the study may be useful for diagnosis and prognosis in patients with alcoholic liver cirrhosis.

\section{Key words}

alcoholic liver cirrhosis, angiopoietin-like peptide 4 (ANGPTL-4), asialoglycoprotein receptor 1 (ASGP-R1), S100 calciumbinding protein A8 (S100A8), hyaluronic acid (Hyal), collagen IV (Coll IV)

\section{INTRODUCTION}

Alcohol consumption causes acute and chronic liver injury. The clinical forms of alcohol liver disease (ALD) include steatosis, hepatitis, cirrhosis, and hepatocellular carcinoma (HCC) associated with liver cirrhosis. The pathogenesis of ALD is complex. The main mechanisms involved include direct cytotoxic effects of ethanol metabolites and the resultant inflammatory reactions, increased permeability of the intestinal barrier leading to the stimulation of the immune system by lipopolysaccharides and bacterial antigens entering the portal circulation, and abnormal regenerative processes with the formation of nodules [1].

The key cells related to fibrogenesis are hepatic stellate cells (HSCs) activated in response to the injurious factor

Address for correspondence: Andrzej Prystupa, Department of Internal Medicine, Medical University, Lublin, Poland

E-mail: aprystup@wp.pl

Received: 03.08.2020; accepted: 18.09.2020; first published: 02.10.2020 and responsible for producing the extracellular matrix constituents. Their activity is modulated by the cytokine network; moreover, they can enhance unaided the inflammatory response by recruitment of leucocytes, as well as release of cytokines and adhesion molecules [2].

Liver biopsy remains the most recognised method of assessing the severity of liver fibrosis and cirrhosis; nevertheless, potential non-invasive markers are intensively searched for. Elastograph, as well as serum biomarkers and tests based on them, may prove particularly useful in this regard [3].

Many cytokines involved in the initiation and progression of fibrosis, as well as the development of cirrhosis, have been identified to date. Proinflammatory and proangiogenic cytokines also play an important role in the above processes [4]. Angiogenesis is activated in numerous pathological conditions of the liver, irrespective of their primary cause (chronic and acute injury, post-partial hepatectomy conditions, ischaemia, hepatocellular carcinoma, and 
metastases) [5]. However, the exact functioning of the cytokine network has not been fully elucidated. Better understanding of the cytokines and their interrelations should facilitate the diagnosis of alcoholic liver cirrhosis as well as prognosis of its course and complications.

In the presented study, the serum levels of some novel markers of fibrogenesis and angiogenesis were determined in patients with alcoholic liver cirrhosis. The novel markers included: angiopoietin-like peptide 4 (ANGPTL-4), asialoglycoprotein receptor 1 (ASGP-R1), and S100 calciumbinding protein A8 (S100A8). Moreover, the levels of hyaluronic acid (Hyal) and collagen IV (Coll IV) were determined at various stages of alcoholic liver cirrhosis.

\section{MATERIALS AND METHOD}

Patients. The study was conducted at the Department of Internal Medicine, Medical University in Lublin, eastern Poland, and included 72 patients with alcoholic cirrhosis from the Lublin province. The study protocol was approved by the Bioethics Committee. All subjects gave their written informed consent for participation in the study.

Liver cirrhosis was diagnosed based on clinical features, history of heavy alcohol consumption, laboratory tests and abdominal ultrasonography. The patients with alcoholic hepatitis, hepatocellular carcinoma, viral and autoimmune diseases were excluded from the study. Other exclusion criteria were: type 2 diabetes, obesity, acute infections (e.g., pneumonia, spontaneous bacterial peritonitis), acute and chronic heart failure (> NYHA I), acute and chronic respiratory disorders resulting in respiratory insufficiency, acute kidney injury and chronic kidney disease (> stage G2). Both clinical assessment and laboratory tests were used to exclude the underlying liver diseases in the control group. The degree of liver cirrhosis was evaluated according to the Pugh-Child criteria (Pugh-Child score), based on which the patients were assigned to one of three groups1) Pugh-Child (P-Ch) A - 21 with stage A, 2) P-Ch B - 23 with stage B and 3) $\mathrm{P}-\mathrm{Ch} \mathrm{C}-28$ with stage $\mathrm{Cliver}$ cirrhosis. The control group consisted of 22 healthy individuals without liver diseases who did not abuse alcohol (Tab. 1 and 2.)

Determinations of fibrogenesis and angiogenesis markers. Blood was sampled, and after centrifugation the serum was collected for further analysis. Determinations of fibrogenesis and angiogenesis markers were performed using enzymelinked immunosorbent assays (ELISA). ELISA was performed using ready-made diagnostic kits and Epoch Microplate Spectrophotometer (BioTek Instrumentals, Inc., Winooski, VT, USA). Angiopoietin like protein 4 (ANGPTL4), asialoglycoprotein receptor 1 (ASGR1) and S100 calcium binding protein A8 (S100A8) levels were determined using Sandwich enzyme immunoassay kits (Cloud Clone Corp., Katy, TX, USA), according to manufacturer's procedure. For the determination of ANGPTL4, two-fold dilution of the sample was used, for the S100A8 determinations - a hundredfold dilution of the samples, while for the ASGR1 assay the samples were not diluted. Serum collagen IV and hyaluronic acid levels were determined using TECOmedical Group (Tecomedical AG, Sissach, Switzerland) immunoassay kits (TECO@ assays for hyaluronic acid (TE1017-2) and collagen IV (TE 1053)). According to the manufacturer's protocol; 50-fold diluted samples were used for hyaluronic acid determinations, while samples were not diluted for collagen IV determinations. The procedure for determining the above parameters corresponded mostly with the following steps:

1) pipetting appropriate amounts of standards, blanks and samples into assay wells covered by antibodies;

2) aspiration and washing of each well;

3) addition of biotin-conjugated antibody specific to the determined molecule;

4) further aspiration and washing of each well;

5) addition of Avidin conjugated to Horseradish Peroxidase (HRP) to each microplate well and incubation;

6) addition of TMB substrate solution to each well;

7) termination of reaction by adding hydrochloric or sulphuric acid solution;

8) spectrophotometric measurements of absorbance of standards and samples at a wavelength $450 \mathrm{~nm}$;

9) calculation of parameters levels using curves constructed for standards (whenever necessary, the results were multiplied by a dilution factor).

Statistical analysis. Statistica 13.3 (TIBCO Software, Inc.) was used for data analysis. Continuous variables were expressed as the mean \pm standard deviation (SD). Before calculations, variables were checked for normality using the Shapiro-Wilk test. To compare the results between more than two groups, one-way ANOVA and Kruskal-Wallis test were used, depending on distribution. Correlations among variables were tested using the Pearson's and Spearman's correlation test, depending on distribution. Qualitative variables are shown as indicators of structure (percentage). For intergroup comparisons, the $\chi^{2}$ test was used. For all tests, $\mathrm{p}<0.05$ was considered as statistically significant.

\section{RESULTS}

Demographic and clinical characteristics of the control and alcoholic liver cirrhosis group are presented in Tables 3 and 4.

The lowest level of ANGPTL-4 was demonstrated in the control group $-4.9 \pm 1.5 \mathrm{ng} / \mathrm{ml}$, which and significantly lower compared to patients with $\mathrm{P}-\mathrm{Ch} \mathrm{B}-33.8 \pm 40.7 \mathrm{ng} / \mathrm{ml} ; \mathrm{p}=0.01$, and $\mathrm{P}-\mathrm{Ch} \mathrm{C}$ cirrhosis, in which the highest level was observed - 41.1 $\pm 42 \mathrm{ng} / \mathrm{ml} ; \mathrm{p}=0.07$ ) (Fig. 1). Similar correlations were found for collagen IV. Its lowest level was determined in the control group $(90.1 \pm 16.4 \mathrm{ng} / \mathrm{ml})$; this level significantly increased in cases of P-Ch A $(653.8 \pm 392 \mathrm{ng} / \mathrm{ml} ; \mathrm{p}=0.02)$, $\mathrm{P}-\mathrm{Ch} \mathrm{B}(709 \pm 422.7 \mathrm{ng} / \mathrm{ml} ; \mathrm{p}=0.004)$ and P-Ch C cirrhosis (622.5 $\pm 385.6 \mathrm{ng} / \mathrm{ml} ; \mathrm{p}=0.004)$ (Fig. 2).

The lowest serum level of hyaluronic acid was observed in the control group - $18.3 \pm 19.1 \mathrm{ng} / \mathrm{ml}$. Its level was found to be significantly elevated in the group with P-Ch A (968.1 \pm 789.1 $\mathrm{ng} / \mathrm{ml} ; \mathrm{p}=0.001$ vs. controls $), \mathrm{P}-\mathrm{Ch} \mathrm{B}(880 \pm 773.3 \mathrm{ng} / \mathrm{ml}$; $\mathrm{p}<0.001$ vs controls) and $\mathrm{P}-\mathrm{Ch} \mathrm{C}$ cirrhosis $(866.3 \pm 650.5 \mathrm{ng} /$ $\mathrm{ml} ; \mathrm{p}<0.001$ ) (Fig. 3).

The lowest level of ASGP-R1 was observed in the control group $-0.68 \pm 0.38 \mathrm{ng} / \mathrm{ml}$, and increased to $2.23 \pm 1.48$ in patients with P-Ch C cirrhosis ( $\mathrm{p}=0.001)$ (Fig. 4).

The level of S100A8 in the control group was $8.7 \pm 2.4 \mathrm{ng} /$ $\mathrm{ml}$ which was significantly lower compared to patients with P-Ch C cirrhosis (12.9 $\pm 6.5 \mathrm{ng} / \mathrm{ml} ; \mathrm{p}=0.001)$ (Fig. 5).

The level of ANGPTL-4 was significantly correlated with that of hyaluronic acid $(\mathrm{r}=0.56, \mathrm{p}<0.05)$ and collagen IV 
Table 1. Demographic and clinical characteristics of patients with alcoholic liver cirrhosis and control group

\begin{tabular}{|c|c|c|c|c|c|}
\hline & \multirow{2}{*}{ Control group $(n=22)$} & \multicolumn{3}{|c|}{ Alcoholic liver cirrhosis $(n=72)$} & \multirow{2}{*}{$\mathrm{p}$} \\
\hline & & Pugh-Child A ( $n=21)$ & Pugh-Child $B(n=23)$ & Pugh-Child C $(\mathrm{n}=28)$ & \\
\hline Age (years) & $43.7 \pm 14.6$ & $57.6 \pm 15.1$ & $56.8 \pm 11.3$ & $57.4 \pm 11.3$ & 0.045 \\
\hline Percentage of males (\%) & $64.3 \%$ & $78.1 \%$ & $80 \%$ & $84.2 \%$ & 0.51 \\
\hline Body weight $(\mathrm{kg})$ & $67.6 \pm 8.9$ & $75 \pm 10$ & $79.7 \pm 10.5$ & $78.8 \pm 11.3$ & 0.13 \\
\hline Height $(\mathrm{cm})$ & $173 \pm 5.9$ & $177.8 \pm 2.6$ & $173.9 \pm 5.8$ & $172.6 \pm 7.8$ & 0.76 \\
\hline Duration of alcohol abuse (years) & - & $16.3 \pm 9.5$ & $23.4 \pm 11.2$ & $22.9 \pm 8.2$ & 0.56 \\
\hline Oesophageal varices (\%) & - & $42.9 \%$ & $40 \%$ & $84.2 \%$ & 0.0004 \\
\hline Encephalopathy (\%) & - & $0 \%$ & $39.1 \%$ & $83.9 \%$ & $<0.0001$ \\
\hline Ascites (\%) & - & $0 \%$ & $60.1 \%$ & $94.7 \%$ & $<0.0001$ \\
\hline
\end{tabular}

Table 2. Biochemical parameters in patients with alcoholic liver cirrhosis and control group

\begin{tabular}{|c|c|c|c|c|c|}
\hline & \multirow{2}{*}{ Control group $(n=22)$} & \multicolumn{3}{|c|}{ Alcoholic liver cirrhosis ( $n=72$ ) } & \multirow{2}{*}{$\mathrm{p}$} \\
\hline & & Pugh-Child A ( $n=21)$ & Pugh-Child B $(n=23)$ & Pugh-Child C ( $n=28)$ & \\
\hline Total bilirubin (mg/dl) & $0.6 \pm 0.3$ & $2.9 \pm 3.2$ & $3.2 \pm 3.4$ & $11.7 \pm 9.7$ & $<0.0001$ \\
\hline International normalised ratio INR & - & $1.3 \pm 0.4$ & $1.4 \pm 0.5$ & $2 \pm 0.6$ & 0.035 \\
\hline Albumin (g/dl) & - & $3.7 \pm 0.6$ & $2.9 \pm 0.6$ & $2.5 \pm 0.5$ & 0.04 \\
\hline Total protein (g/dl) & $6.3 \pm 0.3$ & $6.8 \pm 0.7$ & $6.7 \pm 1.1$ & $5.7 \pm 0.8$ & 0.23 \\
\hline ALT (U/I) & $17.9 \pm 6$ & $36.6 \pm 30$ & $33.7 \pm 26.6$ & $39 \pm 18.7$ & 0.23 \\
\hline AST (U/I) & $18.3 \pm 7$ & $67.4 \pm 51.9$ & $75.2 \pm 33.9$ & $99 \pm 50.6$ & $<0.0001$ \\
\hline $\operatorname{PLT}(\mathrm{G} / \mathrm{l})$ & $231.4 \pm 29.8$ & $178.9 \pm 63.6$ & $168.5 \pm 96.6$ & $123.9 \pm 77.2$ & 0.0004 \\
\hline $\mathrm{MCV}(\mathrm{fl})$ & $84.8 \pm 3.5$ & $86.6 \pm 13.3$ & $88.7 \pm 12.1$ & $94.2 \pm 8.3$ & 0.0003 \\
\hline Urea $(\mathrm{mg} / \mathrm{dl})$ & - & $28 \pm 11.4$ & $29.2 \pm 20.1$ & $67.2 \pm 43.1$ & 0.04 \\
\hline $\mathrm{Na}(\mathrm{mmol} / \mathrm{l})$ & $140 \pm 3.3$ & $135.7 \pm 5$ & $134 \pm 4.3$ & $132.2 \pm 4.4$ & 0.0001 \\
\hline $\mathrm{K}(\mathrm{mmol} / \mathrm{l})$ & $4.4 \pm 0.4$ & $4.2 \pm 0.8$ & $3.9 \pm 0.5$ & $4.2 \pm 0.9$ & 0.6 \\
\hline$\underline{\operatorname{CRP}(\mathrm{mg} / \mathrm{l})}$ & $2.5 \pm 2.3$ & $2.2 \pm 1.3$ & $23.1 \pm 29$ & $35 \pm 29.9$ & $<0.0001$ \\
\hline ANGPTL-4 (ng/ml) & $4.9 \pm 1.5$ & $15.4 \pm 17.3$ & $33.8 \pm 40.7$ & $41.1 \pm 42$ & 0.007 \\
\hline ASGP-R1 (ng/ml) & $0.68 \pm 0.38$ & $1.46 \pm 1.06$ & $1.28 \pm 1.35$ & $2.23 \pm 1.48$ & 0.002 \\
\hline $\mathrm{S} 100 \mathrm{~A} 8(\mathrm{ng} / \mathrm{ml})$ & $8.7 \pm 2.4$ & $13.4 \pm 3.1$ & $12.2 \pm 5.8$ & $12.9 \pm 6.5$ & 0.03 \\
\hline Hyaluronic acid (ng/ml) & $18.3 \pm 19.1$ & $968.1 \pm 789.1$ & $880 \pm 773.3$ & $866.3 \pm 650.5$ & $<0.0001$ \\
\hline Serum collagen IV (ng/ml) & $90.1 \pm 16.4$ & $653.8 \pm 392$ & $709 \pm 422.7$ & $622.5 \pm 385.6$ & $<0.0001$ \\
\hline
\end{tabular}

Table 3. Correlations between ANGPTL-4, hyaluronic acid, collgen IV, S100A8, ASGP-R1 and biochemical and clinical parameters

\begin{tabular}{lccccc}
\hline & \multicolumn{5}{c}{ Parameter } \\
\cline { 2 - 6 } & ANGPTL-4 & Hyaluronic acid & Coll IV & S100A8 & ASGP-R1 \\
\hline Age & 0.23 & $0.34^{*}$ & $0.3^{*}$ & $0.28^{*}$ & 0.28 \\
\hline Duration of alcohol abuse & $0.41^{*}$ & 0.09 & 0.1 & $0.5^{*}$ & 0.37 \\
\hline Total bilirubin & 0.25 & $0.55^{*}$ & $0.41^{*}$ & $0.32^{*}$ & 0.21 \\
\hline ALT & 0.04 & $0.27^{*}$ & 0.19 & -0.05 & -0.15 \\
\hline ASP & 0.22 & $0.52^{*}$ & $0.48^{*}$ & 0.14 & 0.07 \\
\hline Urea & 0.20 & -0.01 & 0.14 & $0.56^{*}$ & 0.27 \\
\hline PLT & $-0.29^{*}$ & $-0.45^{*}$ & $-0.31^{*}$ & -0.21 & $-0.3^{*}$ \\
\hline Na & $-0.42^{*}$ & $-0.27^{*}$ & $-0.39^{*}$ & 0.16 & -0.26 \\
\hline CRP & 0.25 & $0.36^{*}$ & $0.34^{*}$ & 0.18 & 0.07 \\
\hline
\end{tabular}

Table 4. Mutual correlations between ANGPTL-4, hyaluronic acid, collgen IV, S100A8, ASGP-R1.

\begin{tabular}{lccccc}
\hline & \multicolumn{5}{c}{ Parameter } \\
\cline { 2 - 6 } & ANGPTL-4 & Hyaluronic acid & Coll IV & S100A8 & ASGP-R1 \\
\hline Hyaluronic acid & $0.56^{*}$ & - & $0.71^{*}$ & $0.47^{*}$ & $0.31^{*}$ \\
\hline Collagen IV & $0.5^{*}$ & $0.71^{*}$ & - & $0.5^{*}$ & $0.32^{*}$ \\
\hline ANGPTL-4 & - & - & - & $0.59^{*}$ & $0.4^{*}$ \\
\hline ASGP-R1 & - & - & - & $0.57^{*}$ & - \\
\hline
\end{tabular}




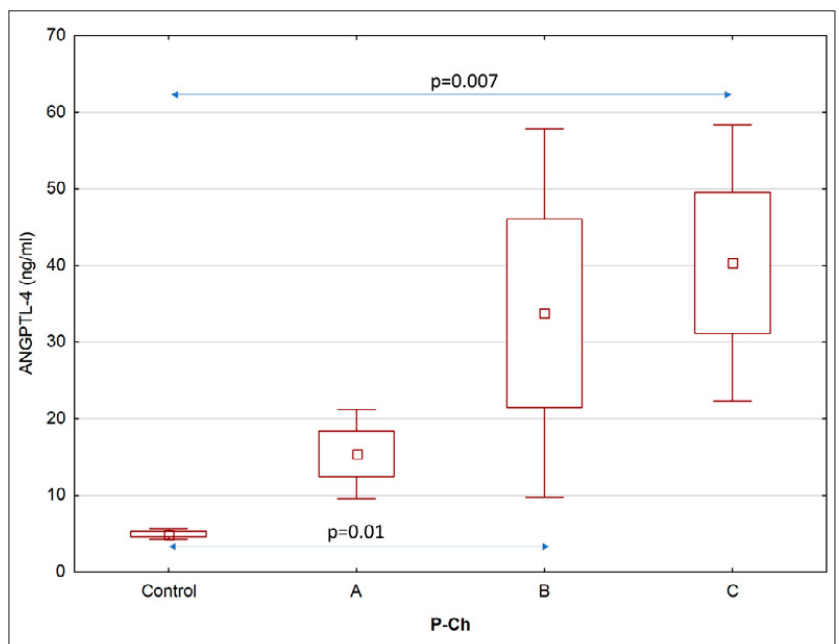

Figure 1. Levels of ANGPTL-4 in control and cirrhosis groups

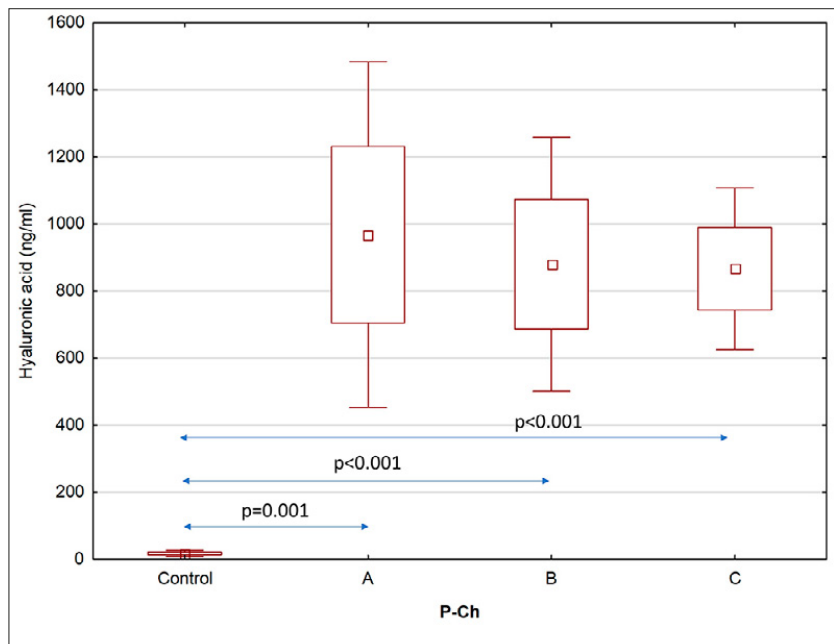

Figure 3. Levels of hyaluronic acid in control and cirrhosis groups

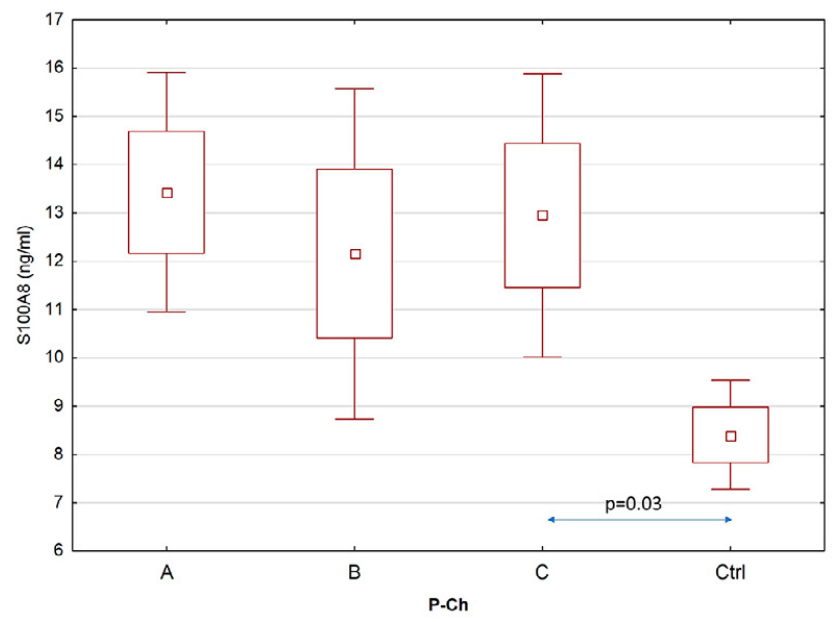

Figure 5. Levels of S100A8 in control and cirrhosis groups

$(\mathrm{r}=0.5, \mathrm{p}<0.05)$. Moreover, significant correlations were demonstrated between the level of hyaluronic acid and that of total bilirubin $(\mathrm{r}=0.55 ; \mathrm{p}<0.05)$, ASP activity $(\mathrm{r}=0.52$, $\mathrm{p}<0.05)$ and collagen IV $(\mathrm{r}=0.71 ; \mathrm{p}<0.05)$. The level of collagen IV was significantly correlated with the level of hyaluronic acid $(r=0.71 ; p<0.05)$. Significant correlations were observed

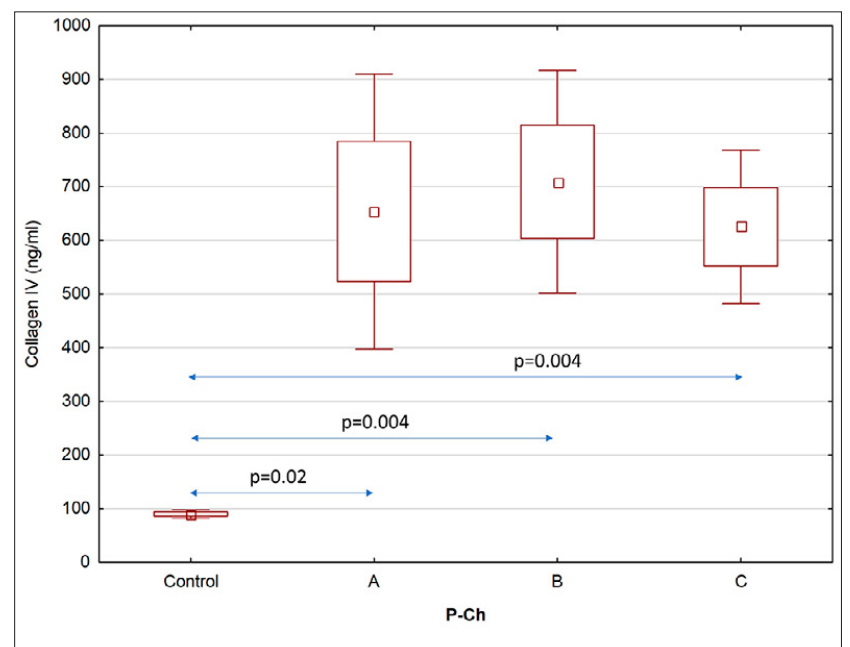

Figure 2. Levels of collagen IV in control and cirrhosis groups

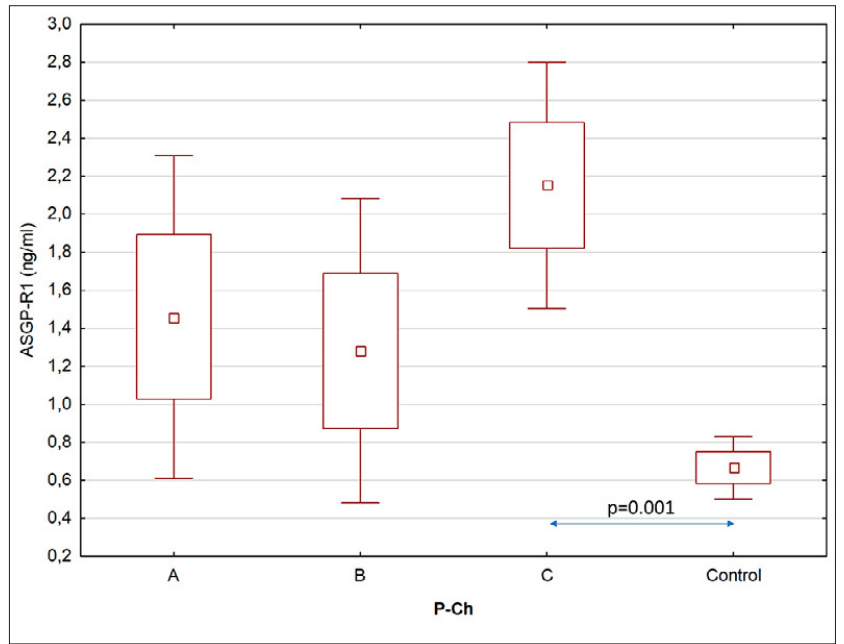

Figure 4. Levels of ASGP-R1 in control and cirrhosis groups

between the level of S100A8 and duration of drinking alcohol $(\mathrm{r}=0.5 ; \mathrm{p}<0.05)$, urea $(\mathrm{r}=0.56 ; \mathrm{p}<0.05)$, collagen IV $(\mathrm{r}=0.5$; $\mathrm{p}<0.05)$ and ANGPTL-4 $(\mathrm{r}=0.59 ; \mathrm{p}<0.05)$. Moreover, the level of ASGP-R1 was significantly correlated with the level of $\mathrm{S} 100 \mathrm{~A} 8(\mathrm{r}=0.57 ; \mathrm{p}<0.05)$. The remaining correlations were weak $(r<0.5)$ or non-significant $(\mathrm{p}>0.05)$.

\section{DISCUSSION}

Hyaluronic acid and collagen IV are the recognised markers of liver fibrosis [6]. Serum levels of collagen IV correlate well with its content in the liver and risk of progression of fibrosis [7]. Hyaluronic acid is the main component of the extracellular matrix. Its increase in serum is observed in liver diseases resulting from the secretion of activated stellate cells reduced clearance [8]. In the current study, the serum hyaluronic acid level was significantly higher in the liver cirrhosis group, compared to the control group.

S100 calcium-binding protein A8 (S100A8) belongs to the family of proteins involved in the regulation of calciumdependent cell processes and acts as a proinflammatory chemokine causing the recruitment of neutrophils to the site of inflammation [9]. The major sources of S100A8 are neutrophils, monocytes and macrophages. Elevated levels 
of S100A8 and S100A9 are observed in many chronic inflammatory diseases, e.g. rheumatoid arthritis, nonspecific enteritis, multiple sclerosis, cystic fibrosis of the pancreas, and psoriasis [10]. Moreover, increased levels of S100A8 are found in inflammatory reactions induced by infection, injury and other stress stimuli. By activating caspase of inflammasomes, bacterial liposaccharides (LPS) promote the release of S100A8 from macrophages [11]. Serhal et al. have demonstrated increased expression of S100A8 in liver bioptates in patients with non-alcoholic steatohepatitis, and elevated serum levels of S100A8 in patients with liver fibrosis [12]. It has also been found that S100A8 may be a factor promoting carcinogenesis in the liver [13].

In the current study, the level of S100A8 was statistically higher in the group of patients with $\mathrm{C}$ cirrhosis $(12.9 \pm 6.5$ $\mathrm{ng} / \mathrm{ml} ; \mathrm{p}=0.001)$, compared to the control group $(8.7 \pm 2.4$ $\mathrm{ng} / \mathrm{ml}$ ). As already mentioned in the introduction, impaired permeability of the intestinal barrier characteristic of alcoholic liver cirrhosis increases the level of LPS in portal blood and may lead to up-regulation of S100A8. It could be suggested that S100A8 is induced by pro-inflammatory factors yet the protein itself may enhance this reaction, promote fibrosis and increase the risk of neoplasia.

Asialoglycoprotein receptors (or Aswell-Morell receptors) are located on the surface of hepatocytes and are of importance in the hepatic catabolism of proteins [14]. The expression of ASGP-R1 increases when affected by proinflammatory cytokines [15]. According to Zhang et al., the expression of ASGP-R correlated with the progression of liver fibrosis in a mouse model of toxic liver injury [16]. Furthermore, Witzigmann et al. have shown that the expression of ASGP-R1 was higher in cirrhotic liver specimens; according to the authors, this increased expression may be associated with the immune response [17], which is consistent with the findings of the current study. In this study, increased serum levels of ASGP-R1 were observed in patients with P-Ch C liver cirrhosis $(2.23 \pm 1.48)$, compared to the control group $0.68 \pm 0.38 \mathrm{ng} / \mathrm{ml}(\mathrm{p}=0.001)$. These findings also demonstrated correlations with the markers of fibrosis, i.e. hyaluronic acid $(\mathrm{r}=0.31 ; \mathrm{p}<0.05)$ and collagen IV $(\mathrm{r}=0.32 ; \mathrm{p}<0.05)$.

It can therefore be assumed that the level of ASGP-R1 in alcoholic liver disease results from both the action of proinflammatory cytokines and inhibiting effects of ethanol. It cannot be excluded that at various stages of disease, the relation changes dynamically. In this study, patients with steatosis and hepatitis, as well as alcoholics without overt liver diseases, were not analysed; hence, any possible changes in ASGP-R level were indefinable.

ANGPLT-4 was the final marker determined. This peptide is essential in the metabolism of lipids by inhibiting the activity of lipoprotein lipase [18]. The expression of ANGPTL-4 was observed in various cells, such as adipocytes, hepatocytes, myocytes or endothelial cells. To date, the research has been mainly focused on the role of ANGPTL-4 in metabolic diseases and dyslipidaemias [19]. The proangiogenic action of ANGPTL-4 has been demonstrated, inter alia, in adipose tissue [20].

A study assessing individuals who had routine follow-ups has demonstrated that the level of ANGPTL- 4 correlated with the activity of transaminases and cholestatic enzymes [21]. To the best of the knowledge of the authors of the current study, only two published papers have dealt with the role of ANGPTL-4 in non-alcoholic steatosis. According to one of the studies, the level of ANGPTL-4 was lower in patients with steatosis than in the control group [22]; in the other study from the same centre, no association between the serum level of ANGPTL-4 and hepatosteatosis in adolescents was demonstrated [23].

According to the findings of the current study, the level of ANGPLT-4 was elevated in the group of patients with alcoholic liver cirrhosis, compared to the control group. The highest level of ANGPLT- 4 was observed in P-Ch C cirrhosis. It is worth stressing that steatosis, which is usually the first symptom of alcoholic lever cirrhosis, represents another pathogenetic stage. Moreover, a positive correlation was demonstrated between the level of ANGPTL-4 vs. duration of excessive alcohol use $(\mathrm{r}=0.41 ; \mathrm{p}<0.05)$ as well as markers of fibrosis - hyaluronic acid $(r=0.56 ; \mathrm{p}<0.05)$ and collagen IV $(\mathrm{r}=0.5 ; \mathrm{p}<0.05)$. In the presented study, levels of lipoproteins, serum free fatty acids, glycaemia and insulinaemia were not tested; therefore, their possible effects on ANGPTL-4 cannot be defined. The expression of ANGPTL- 4 was found to increase due to the acute phase response [24]. These results did not reveal a correlation of ANGPTL-4 with the CRP level; otherwise, its positive correlation with S100A8, also an inflammatory marker, was observed $(\mathrm{r}=0.59 ; \mathrm{p}<0.05)$.

According to one study, the levels of ANGPTL-4 and-3 were elevated in patients with hepatocellular carcinoma [25]. Since angiogenesis is essential for the process of neoplasia, it could be suggested that the level of ANGPTL-4 may to be a marker of increased risk of hepatocellular carcinoma and be pathogenetically involved [26, 27]. Further prospective studies are needed to verify the prognostic value of ANGPTL-4 in patients with alcoholic liver cirrhosis.

\section{CONCLUSIONS}

The presented study findings demonstrate that the levels of ANGPTL-4, ASGP-R1, S100A, hyaluronic acid and serum collagen IV were increased in the group of patients with alcoholic liver cirrhosis, compared to controls. Moreover, their levels were found to increase with disease progression. Future research should verify the usefulness of these biomarkers in the diagnosis and prognosis of progression, as well as complications of alcoholic liver cirrhosis.

\section{Acknowledgments}

This study has been performed at Medical University of Lublin, Poland, and it was funded by a Grant from the Medical University of Lublin (DS 507/2013-2015). The authors thank Anna Misiuna, who provided medical writing services on behalf of Medical University of Lublin, Poland.

\section{REFERENCES}

1. Dunn W, Shah VH. Pathogenesis of Alcoholic Liver Disease. Clin Liver Dis. 2016; 20: 445-456.

2. Osna NA, Donohue Jr. TM, Kharbanda KK. Alcoholic Liver Disease: Pathogenesis and Current Management. Alcohol Res. 2017; 38: 147-161.

3. Moreno C, Mueller S, Szabo GJ. Non-invasive diagnosis and biomarkers in alcohol-related liver disease. J Hepatol. 2019 F; 70: 273-283.

4. Prystupa A, Kiciński P, Sak J, Boguszewska-Czubara A, ToruńJurkowska A, Załuska W. Proinflammatory Cytokines (IL-1 $\alpha$, IL-6) and Hepatocyte Growth Factor in Patients with Alcoholic Liver Cirrhosis. Gastroenterol Res Pract. 2015; 2015: 532615.

5. Elpek GÖ. Angiogenesis and liver fibrosis. World J Hepatol. 2015; 7: 377-391. 
6. Friedman SL. Molecular regulation of hepatic fibrosis, an integrated cellular response to tissue injury. J Biol Chem. 2000; 275: 2247-2250.

7. Tsutsumi M, Urashima S, Matsuda Y, Takase S, Takada A. Changes in type IV collagen content in livers of patients with alcoholic liver disease. Hepatology. 1993; 17: 820-827.

8. Gressner AM, Haarmann R. Hyaluronic acid synthesis and secretion by rat liver fatstoring cells (perisinusoidal lipocytes) in culture. Biochem Biophys Res Commun. 1988; 151: 222-229.

9. Nacken W, Roth J, Sorg C, Kerkhoff C. S100A9/S100A8: Myeloid representatives of the $\mathrm{S} 100$ protein family as prominent players in innate immunity. Microsc Res Tech. 2003; 60: 569-580.

10. De Ponti A, Wiechert L, Stojanovic A, Longerich T, Marhenke S, Hogg $\mathrm{N}$, et al. Chronic liver inflammation and hepatocellular carcinogenesis are independent of S100A9. Int J Cancer. 2015; 136: 2458-2463.

11. Wang S, R. Song R, Wang Z, Jing Z, Wang S, Ma J. S100A8/A9 in Inflammation. Front Immunol. 2018; 9: 1298.

12. Serhal R, Hilal G, Boutros G, Sidaoui J, Wardi L, Ezzeddine S, et al. Nonalcoholic Steatohepatitis: Involvement of the Telomerase and Proinflammatory Mediators. Biomed Res Int. 2015; 2015: 850246

13. De Ponti A, Wiechert L, Schneller D, Pusterla T, Longerich T, Hogg N, et al. A pro-tumorigenic function of S100A8/A 9 in carcinogen-induced hepatocellular carcinoma. Cancer Lett. 2015; 369: 396-404.

14. Hoekstra LT, de Graaf W, Nibourg GAA, Heger M, Bennink RJ, Stieger $B$, van Gulik TM. Physiological and biochemical basis of clinical liver function tests: a review. Ann Surg. 2013; 257: 27-36.

15. Nakaya R, Kohgo Y, Mogi Y, Nakajima M, Kato J, Niitsu Y. Regulation of asialoglycoprotein receptor synthesis by inflammation-related cytokines in HepG2 cells. J Gastroenterol. 1994; 29: 24-30.

16. Zhang D, Guo Z, Zhang P, Li Y, Su X, You L, et al. Simplified quantification method for in vivo SPECT/CT imaging of asialoglycoprotein receptor with $(99 \mathrm{~m}) \mathrm{Tc}-\mathrm{p}$ (VLA-co-VNI) to assess and stage hepatic fibrosis in mice. Sci Rep. 2016; 6: 25377.

17. Witzigmann D, Quagliata L, Schenk SH, Quintavalle C, Terracciano LM, Huwyler J. Variable asialoglycoprotein receptor 1 expression in liver disease: Implications for therapeutic intervention. Hepatol Res. 2016; 46: 686-696.
18. Morinaga J, Zhao J, Endo M, Kadomatsu T, Miyata K, Sugizaki T, et al. Association of circulating ANGPTL 3, 4, and 8 levels with medical status in a population undergoing routine medical checkups: A crosssectional study. PLoS One 2018; 13: e0193731.

19. Barja-Fernández S, Folgueira C, Castelao C, Pena-León V, GonzálezSaenz P, Vázquez-Cobela R, et al. ANGPTL-4 is Associated with Obesity and Lipid Profile in Children and Adolescents. Nutrients 2019; 11: 1340.

20. Gealekman O, Guseva N, Hartigan C, Apotheker S, Gorgoglione M, Gurav K, et. al. Depot-specific differences and insufficient subcutaneous adipose tissue angiogenesis in human obesity. Circulation. 2011; 123: $186-194$.

21. Morinaga J, Zhao J, Endo M, Kadomatsu T, Miyata K, Sugizaki T, et al. Association of circulating ANGPTL 3, 4, and 8 levels with medical status in a population undergoing routine medical checkups: A crosssectional study. PloS One 2018; 13: e0193731.

22. Altun Ö, Dikker O, Arman Y, Ugurlukisi B, Kutlu O, Cil EO, et al. Serum Angiopoietin-like peptide 4 levels in patients with hepatic steatosis. Cytokine 2018; 111: 496-499.

23. Dikker O, Çetin Dağ N, Şahin M, Türkkan E, Dağ H. The association of angiopoietin-like peptide 4 levels with obesity and hepatosteatosis in adolescents. Cytokine 2020; 125: 154802.

24. Lu B, Moser A, Shigenaga JK, Grunfeld C, Feingold KR. The acute phase response stimulates the expression of angiopoietin like protein 4. Biochem Biophys Res Commun. 2010; 391: 1737-1741.

25. El-Shal AS, Zidan HE, Rashad NM, Wadea FM. Angiopoietin-like protein 3 and 4 expression 4 and their serum levels in hepatocellular carcinoma. Cytokine 2017; 96: 75-86.

26. Ng K TP, Xu A, Cheng Q, Guo DY, Xue-Hui Lim Z, Kin_wai Sun Ch, et al. Clinical relevance and therapeutic potential of angiopoietin-like protein 4 in hepatocellular carcinoma. Mol Cancer. 2014; 13: 196.

27. Li H, Ge C, Zhao F, Yan M, Hu Ch, Jia D, et al. Hypoxia-inducible factor 1 alpha-activated angiopoietin-like protein 4 contributes to tumor metastasis via vascular cell adhesion molecule-1/integrin $\beta 1$ signaling in human hepatocellular carcinoma. Hepatology 2011; 54: 910-919. 